\title{
SATISFACTION WITH LIFE AND MENTAL HEALTH OF INDIAN ARMED FORCES
}

\author{
Dr. Pooja Varma \\ Assistant Professor, Psychology, Jain (Deemed to be University), \\ Bangalore, Karnataka. \\ Lieutenant Col. Ashok Kumar \\ Officer Commanding, 358 (I) Comp Pl ASC, PIN-905358 C/O 56 APO.
}

\begin{abstract}
For each individual, mental health is affected by various factors, his working environment, experiences, societal arrangement, resources, inter action and inter person relations and cultural values. The mental health of the armed forces who almost render prime time of their life to the nation has been investigated primarily in terms of inpatient psychiatric diagnosis or psychiatric interviews. These investigations are not in routine and do not speak about the wellbeing of soldiers in their daily routine life, nor there is any continuity of investigating about the mental health of the soldier post recruitment till such time any severity demands professional intervention of a psychiatrists. Moreover, there are dearth of recent researches in India based on assessment of mental health of armed forces and their satisfaction with life when at the zenith of their career. The present investigation selected under consideration are JCO's and NCO's (Middle and Higher) rank personnel of ASC Centre \& College, Bangalore at their pre-retirement stage within next 12 months were contacted with proper consent. To accomplish the objectives of the present investigation, descriptive statistics was computed which included Mean and S.D. for each of the variables, followed by Person's product moment correlation of coefficient and linear regression analysis. The implications of the present investigation can be implemented at the Indian Defence service stations to assess the mental health at regular intervals conducive to maintan the contentment in their life which is directly linked to their performance during peace time and operations.
\end{abstract}

Key Words: Mental Health, Life satisfaction, Indian Armed forces, Pre-retirement.

\section{INTRODUCTION}

Mental Health is a level of psychological wellbeing or an absence of mental illness- the state of someone who is functioning at a satisfactory level of emotional and behavioral adjustments. The factors that contribute to the frequent occurrence of favorable mental health symptoms are expressed in a general feeling of well- being, self-confidence, personal competence, satisfaction with life or job or relations, positive effect, emotional bonds in social relationships, happiness and ego- strength.

Maddox (1987) in the encyclopedia of aging defined life satisfaction as subordinate construct of subjective wellbeing (SWB), others being happiness, mood and morale. It is contentment with one's life in general. Research points out that there are individual differences in how meaning in life is to one's sense of wellbeing. The determinants of well-being and life satisfaction are highly individualized or personalized. It is up to an individual to be satisfied depending on his value orientations.

Defense Institute of Psychology Research (DIPR) is the nodal agency which regularly carries out the research on the issues affecting the life of soldiers in the defense services. It not only ensures recruitment of personnel who are mentally healthy by administering various psychological tests during the process of recruitment but also recommends others psychological tests for checking the aptitude and attitude to allot them the tasks and trade according to individuals' skills for better productivity and efficiency. There is no continuity of monitoring of state of wellbeing of these soldiers subsequent to their joining units and their performance other than those psychiatric cases reported on medical grounds. Nor there is any continuity in research recording their wellbeing and satisfaction of life. Keeping these factors in mind, it necessitated this research to ascertain the mental Health and 


\section{International Journal of Engineering Applied Sciences and Technology, 2020 \\ Vol. 4, Issue 10, ISSN No. 2455-2143, Pages 372-376 \\ Published Online February 2020 in IJEAST (http://www.ijeast.com)}

satisfaction component. Currently, personnel of Other Ranks (ORs) start retiring after 15 to 17 years of service or by the time they are 35 to 37 . For officers, the retirement age is 54, unless they get promoted to higher ranks.

Everyone has feelings of anxiety at some point in their life-for example, a soldier may feel worried and anxious about going for a combat operation or having some domestic problem at home. During these circumstances, feeling anxious can be perfectly normal. Some anxiety is helpful- it activates our reflexes and focuses our attention to be prepared for the impending potential threat etc. It usually settles down once the stressful situation has passed. But some soldier finds it hard to control their worries. Their feelings of anxiety are more constant and it makes hard for them to cope up with their daily lives.

Abundance of literature supporting the relationship between psychological well-being and physical health has spurred a growing interest as to how different forms of psychological well-being can impact one's physical health and performance. Available research consistently propagated that mental health (psychological well-being and distress) of armed forces is important and directly linked to their performance during peace time and operations. Apparently, there are dearth of research depicting the real picture of psychological state of armed forces who would have given prime time of their life to the nation, therefore it necessitated the need to assess and interview them on their life experiences.

\section{METHODOLOGY}

\section{Participants and Procedure}

The objectives were to assess the life satisfaction and level of mental health among armed forces, to examine the relationship between mental health with life satisfaction and to identify the contribution of mental health towards the prediction of satisfaction with life for those who are at their pre-retirement stage. In order to accomplish the objectives of the present empirical investigation the "ex-post factor research design" was employed. In the present investigation 93 armed forces (JCO's and NCO's) of ASC Centre \& College, Bangalore those who are approaching towards job maturity within next 12 months were contacted with proper consent. Those volunteers were ensured about the confidentiality related to their demographic information and survey responses. Rapport was established with each participant and they were provided with the psychological measures (MHI-38 \& SWLS) and instructions were given for each measure separately.

\section{Ethical considerations.}

To maintain the confidentiality of the defence personnel, their demographic information (viz., age, gender, domicile, unit, division, positing, rank hierarchy) have not been utilized to interpret the results.

\section{Hypothesis}

The dimension of mental health would be positively related with satisfaction and mental health would positively contribute towards the prediction of satisfaction with life among armed forces.

\section{MATERIALS}

The Mental Health Index (Davies, Sherbourne, Peterson, \& Ware, 2003) consist of 38 items which has been designed to measure mental health of general as well as clinical adolescent or adult population with the help of global mental health index. In addition to the global mental health the scale measures The Psychological Distress (PD) and Psychological Well-being (PWB) global scales represent complementary summary scales with psychological distress. The Satisfaction with Life Scale (SWLS), Diener, Emmons, Larsen, \& Griffin (1985) is a 5-item scale designed to measure global cognitive judgments of one's life satisfaction (not a measure of either positive or negative affect).

\section{RESULTS}

To accomplish the objectives of the present investigation descriptive statistics was computed which included Mean and S.D. for each of the variables. The descriptive statistics followed by Person's product moment correlation of coefficient and linear regression analysis.

Hence, the objective of the present investigation to assess the level of mental health and satisfaction with life among armed forces at pre-retirement stage. To accomplish this objective descriptive statistics have been calculated (Table 1) which gives the relation of mental health with satisfaction with life among armed forces at preretirement stage. To accomplish present objective, coefficient of correlation was computed by employing Pearson's Product Moment Method (Table 2). 
International Journal of Engineering Applied Sciences and Technology, 2020

Vol. 4, Issue 10, ISSN No. 2455-2143, Pages 372-376

Published Online February 2020 in IJEAST (http://www.ijeast.com)

Table 1

Summary of descriptive statistics and inter-correlation between SWL and MHI for Armed forces at preretirement stage $(\mathbf{N}=93)$

\begin{tabular}{|l|l|l|l|}
\hline VARIABLES & Mean & S.D. & R \\
\hline Mental Health Index (MHI) & 185.08 & 17.95 & \multirow{2}{*}{$0.39^{* *}$} \\
\hline Satisfaction With Life (SWL) & 27.40 & 3.92 & \\
\hline
\end{tabular}

${ }^{* *}$ Significant at .01 p level (1tailed)

The above table reveals that the mean score (S.D.) obtained by the participants depicted the high scores on the Mental Health Index that accentuates greater psychological well-being and relatively less psychological distress. The raw score range is $38-226$. The obtained mean score on

mental health is 185.08 (S.D. $=17.95$ ) which is quite high as per the norms, indicating less psychological distress and greater psychological well-being among defense personnel. The obtained mean scores in the second variable fall within the range of $26-29$ which refers to the "Satisfied" level of satisfaction with life.

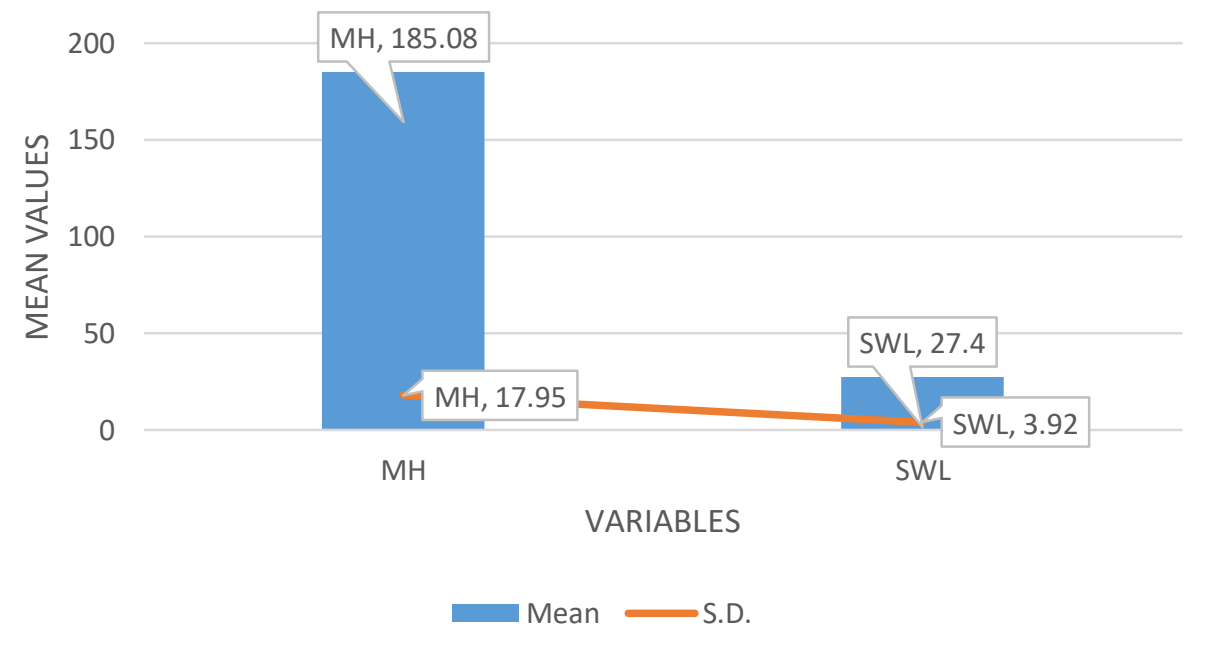

Figure 1: Descriptive statistics (Mean \& S.D.) on MH and SWL (N = 93)

Being positive psychological constructs both mental health and satisfaction with life have been expected to be positively associated with each other. Undoubtedly, the obtained results of intercorrelation are same as they were expected by the research investigator. In Fig. 1, The obtained value of correlation is $0.39(\mathrm{p}<.01)$, though the outcome value indicates significant and positive correlation, but strength of association is weak.

Therefore, hypothesis stating that "Mental health would be positively related with satisfaction with life among armed forces at their preretirement stage" has been accepted and being supported by the previous findings.

Table 2

Summary of Linear regression analysis for Satisfaction with life (DV) and Mental health index (IV) for Armed forces at preretirement stage $(\mathrm{N}=93)$

\begin{tabular}{|c|c|c|c|c|c|}
\hline \multirow{2}{*}{ VARIABLES } & \multirow{2}{*}{ a Constant } & \multicolumn{2}{|c|}{ MHI } & \multirow{2}{*}{$\mathbf{R}^{2}$} & \multirow{2}{*}{$\mathbf{F}$ for $R^{2} \Delta$} \\
\hline & & $b$ & Beta & & \\
\hline Mental Health Index & 11.45 & 0.09 & 0.39 & 0.16 & $16.80^{* * *}$ \\
\hline
\end{tabular}

\footnotetext{
.01 p level (1-tailed)
} 
It is evident fromTable 2 depicting linear regression that mental health is emerged as the positive significant predictor (beta $=0.39$ ) of satisfaction with life and contributed almost $16 \%$ of the variance towards the same out of the total variance. This trend indicates that if mental health have been promoted among the defense personnel their satisfaction with life would ultimately enhance. The same has been highlighted with the help of pie-chart.

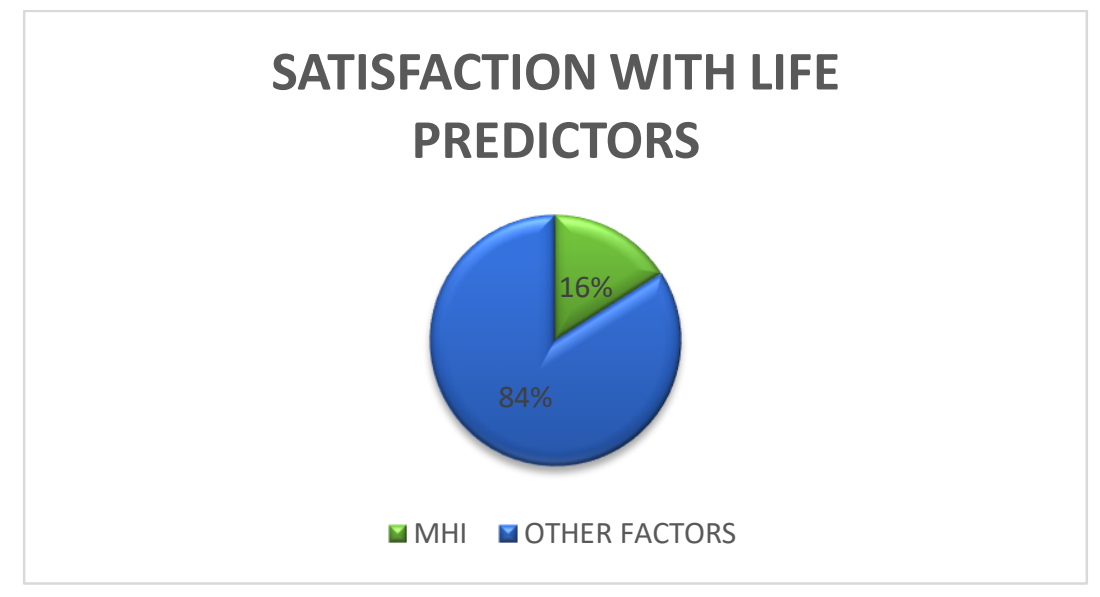

Figure 2: Pie chart highlighting \% of variance contributed by MHI as predictor towards SWL

Therefore, hypothesis stating that mental health would positively contribute significant amount of percentage of variance towards the prediction of satisfaction with life among armed forces at pre-retirement stage.

\section{DISCUSSION}

Since Indian armed forces usually spent their quality life-time in the service of the nation, it has been observed that those who possess better mental health can build stronger emotional bonds with their superiors and subordinates, experience general positive affect, satisfied with their life and found to be high on psychological well-being. Whereas, armed forces who frequently experience anxiety, depressive symptoms, loss of behavioral/emotional control in stressful situations report frequent occurrence of negative mental health symptoms viz. they are high on psychological distress (Pawar \& Rathod, 2007; Ahmadi \& Alireza, 2007; Chaturvedula \& Joseph, 2007; Ryali et al., 2011; Blaketley et al., 2013).

People who score high on life satisfaction tend to have close and supportive family and friends, whereas those who do not have close friends and family are more likely to be dissatisfied. As might be expected that the loss of a close friend or family member is a seed of dissatisfaction with life, and it may yield quite a time for the person to bounce back from the loss.

Another imperative factor to life satisfaction is one's dedication to work, paramount role of homemaker, grandparent and so forth.
When the person savour his or her momentous work, whether it is paid or unpaid work, and discern it as consequential,worthwhile and instrumental to life satisfaction. When work is going abysmally owing to the fact of dire circumstances or a poor fit with the person's strengths can lower delectation and life satisfaction. When a person own significant bourne, and fails to make adequate progress toward them, can too lead to life dissatisfaction.

There is no one key to life satisfaction, but rather a recipe that includes a number of ingredients out of which one is better mental health. With time and persistent work, people's life satisfaction usually goes up when they are dissatisfied. People who have had a loss recover over time. People who have a dissatisfying relationship or work often make changes over time that can escalate their dissatisfaction. One key ingredient to happiness, as mentioned above, is social relationships, and another key ingredient is to have important goals that derive from one's values, and to make progress toward those goals. For many people it is important to feel a connection to something larger than oneself. When a person tends to be chronically dissatisfied, they should look within themselves and ask whether they need to develop more positive attitudes to life and the world.

It was reported that the diagnoses of mental health conditions among active duty service members increased substantially relative to nondeployed service members. This increase was due to the psychological toll of exposure to conflict. It 


\section{International Journal of Engineering Applied Sciences and Technology, 2020 \\ Vol. 4, Issue 10, ISSN No. 2455-2143, Pages 372-376 \\ Published Online February 2020 in IJEAST (http://www.ijeast.com)}

was also emphasized that increased and improved screening methods as well as Department of Defense (DOD) efforts to reduce the stigma associated with seeking mental health treatment, that might dissuade some service members reporting mental health concerns or accessing care, could be also contributory towards increase in numbers of mental health problem cases. The study also highlighted the importance of counseling and mental health care but the reliable evidence were found lacking as to the quality of mental health care and counseling offered in DOD facilities (Blaketley et al., 2013; Cigrang et al., 2000, 2001; DIPR, 2000-2005; Mathur, 2007; National Institute of Mental Health ,1999).

\section{CONCLUSION}

For many people it is important to feel a connection to something larger than oneself. When a person tends to be chronically dissatisfied, they should look within themselves and ask whether they need to develop more positive attitudes to life and the world. The findings of the present investigation can be implemented at the Indian Defence service stations to assess the mental health at regular intervals as this would help to understand the various components of mental health (anxiety, stress, depress, emotional ties, psychological distress, psychological well-being) which might be leading to satisfaction with life of an individual in different ways. Assessment of mental health at regular is very important and defence personnel must be provided with psycho-educational programs for the improvement of mental health. Participants those who scored poor mental health must be identified and proper psychological counselling must be provided to them by the experts.

\section{REFERENCES}

1. Ahmadi, K. and Alireza, K. (2007). Stress and Job Satisfaction among Air force Military Pilots. Journal of Social Sciences. Vol. 3, Issue 3, Pages 159-163.

2. Blakeley, Katherine, and Don J. Jansen (2013). Post-Traumatic Stress Disorder and

Other Mental Health Problems in the Military: Oversight Issues for Congress, Congressional Research Service, 7-5700.

3. Maddox, G. (1987). Aging differently. The Gerontologist, 27(5), 557-564.

4. Cigrang, J. A., Todd, S. L., \& Carbone, E. G. (2000). Stress management training for military trainees returned to duty after a mental health evaluation: Effect on graduation rates. Journal of Occupational Health Psychology, 5, 48-58.

5. Cigrang, J., Talcott, G. W., Tatum, J., Baker, M., Cassidy, D., Sonnek, S., Slep, A. (2011). Psychological health and intimate relationship functioning across the deployment cycle in a cohort of active - duty service members. In D. K. Snyder (Chair), Emerging evidence regarding post - traumatic stress disorder and relationship functioning in OEF/OIF combat veterans. Symposium presented at the meeting of the Association for Behavioral and Cognitive Therapies, Toronto, Canada.

6. Chaturvedula, S. \& Joseph, C. (2007). Dimensions of Psychological Well-Being and Personality in Military Aircrew: A preliminary study. Ind J Aerospace Med., 51 (2): 17-27.

7. Davies, A. R., Sherbourne, C. D., Peterson, J. R., \& Ware, J. E. Jr., (1988). Scoring manual: Adult health status and patient satisfaction measures used in $R A N D$ 's health insurance experiment. CA: Springer.

8. Defence Institute of Psychological Research (DIPR)(2000 - 2005). Psychosocial aspect of optimizing the operational efficiency of Security Forces to combat insurgency. Cf. Dixit, K. C. (2011). Addressing Stress - Related Issues in Army. Institute for Defence Studies and Analyses (IDSA), New Delhi, India.

9. Diener, E., Emmons, R. A., Larsen, R. J., \& Griffin, S. (1985). The Satisfaction with Life Scale. Journal of Personality Assessment, 49, 71-75.

10. Mathur P. (2007). Mental health care for better living. Journal of Indian Health Psychology, 1(2), 151-166.

11. National Institute of Mental Health (1999). A report of the surgeon general: US department of health and human services. Bethesda, MD.

12. Pawar, A. A., \& Rathod, J. (2007). Occupational Stress in Naval Personnel. Military Journal of Armed forces India, 63(2), 154-156.

13. Ryali, S; Bhat, P.S. and Srivasatava, K. (2011). Stress in the Indian Armed forces: How true what to do? MJAFI, 67: 209211. 